\title{
First record of three plant parasitic nematode species from Mount Ararat (Ağrı) in Turkey ${ }^{1}$
}

\author{
Türkiye bitki paraziti nematod faunası için Ağrı Dağı (Ağıı)'ndan 3 yeni kayıt
}

Taylan ÇAKMAK ${ }^{2}$

Çiğdem GÖZEL ${ }^{3}$

\author{
M. Bora KAYDAN ${ }^{4,5}$
}

Uğur GÖZEL $3^{*}$

\begin{abstract}
In this study, plant parasitic nematode fauna from Mount Ararat was determined according to altitude. A total of 30 soil samples were taken in 2013 during summer. Nematodes were extracted by a modified Baermann funnel technique. Nematodes were identified by morphology, morphometric and phylogenetic analysis based on sequences of the D2-D3 and ITS1-rRNA gene sequences. Permanent slides of individuals were made and species-specific characters were screened by scanning electron microscopy (SEM). SEM studies were processed at the Department of Animal Biology, Vegetal Biology and Ecology, SEM laboratory University of Jaén in Spain during 2014. A total of 19 plant parasitic nematodes were identified from Mount Ararat. Three plant parasitic nematodes Rotylenchus conicaudatus Atighi et al., 2011 (Nematoda: Hoplolaimidae), Heterodera trifolii Goffart, 1932 (Nematoda: Heteroderidae) and Tylenchorhynchus mangiferae (Luqman \& Khan, 1986) (Nematoda: Belonolaimidae) from this study are new records for plant parasitic nematode fauna of the Turkish.
\end{abstract}

Keywords: Morphometrics, nematode fauna, new record, phylogeny, Turkey

\section{Öz}

Bu çalışmada Ağıı Dağı bitki paraziti nematod faunası yüksekliklere bağlı olarak belirlenmiştir. Toplam 30 toprak örneği 2013 yılında yaz döneminde alınmıştır. Nematodlar alınan toprak örneklerinden geliştirilmiş Baermann huni yöntemi ile elde edilmiştir. Nematodların tür teşhisleri morfolojik karakterler, morfometrik ölçümler ve moleküler olarak rDNA'nın D2-D3 ve ITS1 bölgelerinin sekans analizleri yapılarak belirlenmiştir. Elde edilen bireylerin daimî preparatları yapılarak türe özgü karakterler taramalı elektron mikroskobu (SEM) ile görüntülenmiştir. SEM çalışmaları İspanya'da Jaen Üniversitesi, Hayvan ve Bitki Biyolojisi ve Ekolojisi Bölümü, SEM laboratuvarında 2014 yılında yapılmıştır. Ağrı Dağı'ndan toplam 19 bitki paraziti nematod türü belirlenmiştir. Bu çalışmada elde edilen bitki paraziti nematodlardan Rotylenchus conicaudatus Atighi et al., 2011 (Nematoda: Hoplolaimidae), Heterodera trifolii Goffart, 1932 (Nematoda: Heteroderidae) ve Tylenchorhynchus mangiferae (Luqman \& Khan, 1986) (Nematoda: Belonolaimidae) türleri Türkiye bitki paraziti nematod faunası için ilk kayıt niteliğindedir.

Anahtar sözcükler: Morfometrik, nematod faunası, yeni kayıt, filogeni, Türkiye

\footnotetext{
${ }^{1}$ This study was supported by Ghent University, Belgium.

2 Instituto Canario de Investigaciones Agrarias (ICIA), Departamento de Protección Vegetal, Valle de Guerra, Tenerife, 38270, España

${ }^{3}$ Çanakkale Onsekiz Mart University, Faculty of Agriculture, Department of Plant Protection, 17100, Çanakkale, Turkey

${ }^{4}$ Çukurova University, Biotechnology Application and Research Centre, 01330, Balcalı, Adana, Turkey

5 Çukurova University, İmamoğlu Vocational School, 01330 Adana, Turkey

* Corresponding author (Sorumlu yazar) e-mail: ugozel@comu.edu.tr

Received (Alınış): 28.02.2019 Accepted (Kabul ediliş): 22.03.2019

Published Online (Çevrimiçi Yayın Tarihi): 04.05.2019
} 


\section{Introduction}

Nematodes are highly diverse, complex and biologically specialized metazoans (De Ley et al., 1999). There are estimates of between 40.000 and 10.000 .000 species in the phylum Nematoda (Blaxter et al., 1998). One challenging estimate speculates that there might be as many as 100.000 .000 species, even before considering the cryptic diversity among morphologically indistinguishable taxa (Lambshead, 1993). The key roles of nematodes in agricultural and natural ecosystems, as well as their usefulness for indicator and molecular studies, make them an important focus for taxonomic, ecological, physiological and molecular research.

Turkey is situated between latitudes $35^{\circ}$ and $43^{\circ} \mathrm{N}$, and longitudes $25^{\circ}$ and $45^{\circ} \mathrm{E}$ within subtropical climate zone. Turkey is geographically consisting of seven regions and each region has different climatic conditions. As a result of this, in recent decades, plant parasitic nematode fauna of the Turkish has been studied by several authors and important nematode species were reported (Ökten, 1982; Elekçioğlu et al., 1994; Elekçioğlu, 1996; Kepenekçi \& Ökten, 2000a, b, c; Kepenekçi \& Öztürk, 2000; Ökten et al., 2000; Erdal et al., 2001; Gözel \& Yıldız, 2015; Mıstanoğlu et al., 2015; Muşdağı \& Gözel, 2015; Aydınlı, 2018). Also, Kepenekçi (2014) published a detailed list of 240 nematode species of plant parasitic nematodes belonging to 56 genera of Tylenchida from Turkey.

Various biogeographic reasons explain the unique diversity met in Turkey's nature. Due to its "crossroad" location and the variations of its geographic features and climatic conditions, Turkey has a rich biodiversity. Another factor, that has shaped Turkey's biodiversity is the ice ages ranging from 1.8 million to ten thousand years ago. The global map of biodiversity hotspots clearly reflects this richness. Three out of 34 biodiversity hotspots meet in Turkey and one of them is the Irano-Anatolian spot.

The Mount Ararat (Ağrı) (5137 m) is the highest mountain in Turkey. As a result of its geographical conditions, the nematode fauna has not been studied to date. In the present study, a total of 2.560 of nematodes were identified. Three new reports for Turkey, Rotylenchus conicaudatus Atighi et al., 2011 (Nematoda: Hoplolaimidae), Heterodera trifolii Goffart, 1932 (Nematoda: Heteroderidae) and Tylenchorhynchus mangiferae (Luqman \& Khan, 1986) (Nematoda: Belonolaimidae) are described from the Mount Ararat. Detailed morphological and morphometric characterization of the taxa are discussed and molecular comparison with closely related Rotylenchus and Heterodera species using the ITS1 of rRNA and D2-D3 of 28S gene sequences is provided.

\section{Material and Methods}

\section{Sampling}

Nematodes were collected from the root zone of wildflower meadows, mountain grasslands, riverbeds, chalk grasslands, igneous soil and marshland from 1523 to $4957 \mathrm{~m}$ a.s.l. on Mount Ararat

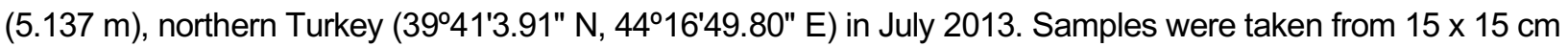
quadrats, placed into ziplock sampling bags and stored in portable cooler during the transport to the laboratory for extraction.

\section{Extraction}

Nematodes were extracted by using a modified Baermann (1917) funnel technique. After separating rocks and large organic particles, further processing was done based on improving the uniformity of samples of equal volume in $200 \mathrm{ml}$ beakers. Samples were then placed on plastic trays lined with paper towels and incubated on the laboratory. Nematodes were collected after $48 \mathrm{~h}$ by pouring the extraction tray over a 500 mesh sieve ( $25 \mu \mathrm{m}$ opening) and put into DESS solution according to Yoder et al. (2006). Each extract was then labeled with corresponding sample number and transported in plastic tubes to the University of Jaén, Spain. 


\section{Preparation of nematodes for light microscope}

After picking out individuals, the nematodes were rinsed with purified water to remove the debris. Glass staining blocks with extracted nematodes were then placed in an airtight jar with $1.25 \mathrm{~cm}$ deep volume of $96 \%$ ethanol, a few drops of glycerol-formalin (4\%) (1:99) was added and the specimens left overnight at room temperature. Next morning, the glass blocks were removed from the jars and a few drops of five parts glycerol and 95 parts $96 \%$ ethanol solution added. Two-thirds of cavity in the glass blocks covered with a glass square and it was placed in an incubator at $40^{\circ} \mathrm{C}$. For gradual transition of glycerin, a few drops of glycerol-ethanol (5:95) solution was added every $2 \mathrm{~h}$. The next day, individual nematodes were permanently mounted on glass slides (Yoder et al., 2006).

\section{Scanning Electron Microscopy}

Fixed individual specimens were rinsed into deionized water to remove all traces of fixatives. After $2 \mathrm{~h}$ for dehydration of specimens, nematodes were passage into $100 \%$ ethanol by passing them through series of 25 (overnight), 30,50, 70, 80, 90, 95, 100\% (each for $2 \mathrm{~h}$ ). The next day the specimens were put in acetone for $1 \mathrm{~h}$ before critical point dried with $\mathrm{CO}_{2}$, coated with gold (Abolafia \& Peña-Santiago, 2005) and observed with a Jeol JSM-5800 microscope. SEM studies were done at Department of Animal Biology, Vegetal Biology and Ecology, SEM Laboratory University of Jaén during 2014.

\section{Measurements}

Measurements and drawings were made using a drawing tube attached to an Olympus microscope (Olympus Optical, Tokyo, Japan). Light microscope pictures were taken using a Nikon Eclipse 80i microscope equipped with a Nikon Digital Sight DS-5M digital video camera. Illustrations were prepared based on light microscope drawings using Illustrator ${ }^{\circledR}$ CS3 Extended software, version 10.0 (Adobe Systems, CA, USA).

\section{Molecular characterization}

\section{DNA extraction, PCR and sequencing}

DNA was extracted from single individuals. After initial selection, nematodes were individually picked from the DESS solution, rinsed with deionized water, put in a drop of worm lyses buffer (50 mM $\mathrm{KCl}, 10 \mathrm{mM}$ Tris-Cl pH 8.3, $2.5 \mathrm{mM} \mathrm{MgCl} 2,0.45 \% \mathrm{NP} 40$ and $0.45 \%$ Tween 20), cut into small pieces and after adding $60 \mathrm{\mu g} \mathrm{ml}^{-1}$ Proteinase $\mathrm{K}$, nematodes were placed in a microcentrifuge tube and transferred to $-80^{\circ} \mathrm{C}$ for $10 \mathrm{~min}$. DNA suspension was added to PCR mixture after preparation the tubes by incubating for $1 \mathrm{~h}$ at $65^{\circ} \mathrm{C}$ followed by enzyme deactivation for $10 \mathrm{~min}$ at $90^{\circ} \mathrm{C}$ and centrifugation for $1 \mathrm{~min}$ at $16,000 \mathrm{~g}$. PCR was performed with a final volume of $25 \mu \mathrm{L}$ suspension, containing $2.5 \mu \mathrm{L}$ genomic DNA template, $2.5 \mu \mathrm{L}$ of $10 \times$ reaction buffer with $\mathrm{MgCl}_{2}$, dNTP-mix at $0.2 \mathrm{mM}$ each, $0.5 \mathrm{~m}$ of each primers; D2Ab (5'-ACAAGTACCGTGAGGGAAAGTTG-3'), D3B (5'-TCGGAAGGAACCAGCTACTA-3') for the D2-D3 domain of the large subunit rDNA gene (De Ley et al., 1999) and Vrain2(f) (5'CTTTGTACACACCGCCCGTCGCT-3'), Vrain2(r) (5'-TTTCACTCGCCGTTACTAAGGGAATC-3') for the ITS1-rRNA (Vrain et al., 1992). The PCR amplification was performed with initial denaturation at $94^{\circ} \mathrm{C}$ for $5 \mathrm{~min}$, followed by 35 cycles of $94^{\circ} \mathrm{C}$ for $1 \mathrm{~min}, 54^{\circ} \mathrm{C}$ for $90 \mathrm{~s}$ and $72^{\circ} \mathrm{C}$ for $2 \mathrm{~min}$, and a final extension at $72^{\circ} \mathrm{C}$ for $10 \mathrm{~min}$. PCR products were sized with $1 \mathrm{~kb}$ DNA ladder (Promega, Madison, WI, USA) on a $1 \%$ agarose gel stained with $0.0003 \%$ ethidium bromide. In order to obtain sequences of the forward and reverse DNA strand, PCR products were sent to Macrogen Inc., Amsterdam, the Netherlands and sequencing was done in both directions with the appropriate primers. The sequences were then edited by performing BioEdit 7.0.4.1 (Hall, 1999). These sequences were then aligned with available sequences from Genbank (NCBI). 


\section{Phylogenetic analysis}

D2-D3 domains of 28S and ITS1-rRNA were used for phylogenetic analyses. Previously published sequences were obtained from GenBank to perform phylogenetic reconstruction (Tables 1\&2). Alignment of sequences were checked by using program CLUSTAL W (Thompson et al., 1994). Bayesian phylogenetic inference was performed with MrBayes v3.1.2 (Ronquist \& Huelsenbeck, 2003). The best fitting model with rate variation across sites and a proportion of invariable sites $(G T R+I+G)$ as estimated by Mega 6.0 program model testing 1.0b was performed for entire alignment. Two independent runs were performed for each 3 million generations and the trees were obtained by using the last 1 million generations with well beyond the burn-in value. Final statistics to check two different runs as average standard deviation of split frequencies between the two analyses were convincing as the value approached zero (<0.0012). Geneious (Basic 5.6.7) program was used to visualize the trees.

Table 1. Rotylenchus species and populations used in this study

\begin{tabular}{|c|c|c|c|c|}
\hline \multirow{2}{*}{ Species } & \multirow{2}{*}{ Locality } & \multicolumn{2}{|c|}{ Accession Number } & \multirow{2}{*}{ Reference } \\
\hline & & D2/D3 & ITS-rRNA & \\
\hline R. buxophilus & California, USA & JX015421 & JX015432 & Cantalapiedra-Navarrete et al. (2013) \\
\hline R. conicaudatus & Mazandaran, Iran & HQ700698 & HQ700700 & Atighi et al. (2011) \\
\hline R. eximius & Brindisi, Italy & EU280794 & EU373663 & Cantalapiedra-Navarrete et al. (2013) \\
\hline R. goodeyi & Vejer, Spain & DQ328756 & - & Subbotin et al. (2007) \\
\hline R. incultus & Niebla, Spain & EU280796 & EU373673 & Cantalapiedra-Navarrete et al. (2013) \\
\hline R. iranicus & Mazandaran, Iran & HQ700697 & HQ700699 & Atighi et al. (2011) \\
\hline R. jaeni & Santa Elena, Spain & EU280791 & EU280791 & Cantalapiedra-Navarrete et al. (2013) \\
\hline R. laurentinus & Torre Canne, Italy & DQ328757 & - & Cantalapiedra-Navarrete et al. (2013) \\
\hline R. magnus & Arévalo, Spain & EU280789 & EU373660 & Cantalapiedra-Navarrete et al. (2013) \\
\hline R. magnus & Arévalo, Spain & - & EU373676 & Cantalapiedra-Navarrete et al. (2013) \\
\hline R. montanus & Trentino, Italy & - & EU280801 & Cantalapiedra-Navarrete et al. (2013) \\
\hline R. montanus & Trentino, Italy & DQ328743 & EU280800 & Vovlas et al. (2008) \\
\hline R. paravitis & Jerez, Spain & JX015422 & JX015434 & Cantalapiedra-Navarrete et al. (2013) \\
\hline R. pumilus & California, USA & JX015423 & JX015435 & Cantalapiedra-Navarrete et al. (2013) \\
\hline R. robustus & Lucena del Puerto, Spain & JX015424 & JX015437 & Cantalapiedra-Navarrete et al. (2013) \\
\hline R. uniformis & Bruges, Belgium & DQ328735 & - & Vovlas et al. (2008) \\
\hline R. unisexus & Seville, Spain & - & EU373675 & Vovlas et al. (2008) \\
\hline R. unisexus & Seville, Spain & EU280799 & EU373674 & Vovlas et al. (2008) \\
\hline R. vitis & Montemayor, Spain & JN032581 & JN032582 & Cantalapiedra-Navarrete et al. (2013) \\
\hline Rotylenchus sp. & Russia & - & EU280802 & Vovlas et al. (2008) \\
\hline
\end{tabular}

The phylogenetic relationships of the $R$. conicaudatus isolate from Mount Ararat were inferred from large subunit rDNA sequences (D2/D3 domains of the $28 S$ gene) and ITS-rRNA available from GenBank. 
Table 2. Heterodera species and populations used in this study

\begin{tabular}{|c|c|c|c|}
\hline Species & Locality & $\begin{array}{l}\text { Accession } \\
\text { Number }\end{array}$ & Reference \\
\hline H. trifolii & Iran, Khozestan & GU475089 & Heydari et al. (2010) \\
\hline H. schachtii & Iran, Khorasan & GU475088 & Heydari et al. (2010) \\
\hline H. schachtii & USA, North Dakota & JQ040526 & Nelson et al. (2012) \\
\hline H. schachtii & USA, North Dakota & JQ040527 & Nelson et al. (2012) \\
\hline H. glycines & Iran, Mazandaran & GU475087 & Heydari et al. (2010) \\
\hline H. glycines & China, Gansu province & GU595446 & Peng and Ye (2011) \\
\hline H. glycines & China, Gansu province & GU595450 & Peng \& Ye (2011) \\
\hline H. glycines & China, Gansu province & GU595452 & Peng \& Ye (2011) \\
\hline H. glycines & China, Gansu province & GU595447 & Peng \& Ye (2011) \\
\hline H. glycines & China, Gansu province & GU595448 & Peng \& Ye (2011) \\
\hline H. glycines & China, Gansu province & GU595445 & Peng \& Ye (2011) \\
\hline H. glycines & USA & DQ328692 & Subbotin et al. (2007) \\
\hline H. glycines & Canada, Quebec & KF453623 & Mimee et al. (2014) \\
\hline H. glycines & China & JQ067683 & Peng \& Xu (2013) \\
\hline H. glycines & China, Zhongwei province & HM560850 & Ye et al. (2010) \\
\hline H. glycines & China, Gansu province & JN684907 & Wei et al. (2013) \\
\hline H. glycines & China, Gansu province & JN684906 & Wei et al. (2013) \\
\hline H. avenae & China, Anhui province & HM560801 & Ye et al. (2010) \\
\hline H. avenae & China, Anhui province & GU595436 & Ye et al. (2010) \\
\hline H. avenae & China, Anhui province & GU595437 & Ye et al. (2010) \\
\hline H. avenae & China, Anhui province & GU595438 & Ye et al. (2010) \\
\hline H. cruciferae & Italy, Castellanetta & JX402414 & Sasanelli et al. (2013) \\
\hline
\end{tabular}

\section{Results and Discussion}

\section{Hoplolaimidae}

\section{Rotylenchus conicaudatus Atighi et al. 2011}

Material examined. Mount Ararat, Turkey, 23.VII.2013, 30 우 and $32 \AA \lambda$, altitude 3757, 3754, 3563, 2554 and $2337 \mathrm{~m}$ a.s.I., in mountain grassland. 
Description (Table 3).

Table 3. Main morphometric data of Rotylenchus conicaudatus from Mount Ararat (measurements in $\mu \mathrm{m}$ )

\begin{tabular}{|c|c|c|c|}
\hline Characters & q & 우우 & $\widehat{\partial} \sigma^{\lambda}$ \\
\hline $\mathrm{n}$ & 1 & 30 & 32 \\
\hline $\mathrm{L}(\mu \mathrm{m})$ & 735.0 & $780.0 \pm 38.0(724-882)$ & $722.0 \pm 27.0(671-772)$ \\
\hline a & 26.9 & $28.1 \pm 0.9(27.3-30.4)$ & $32.1 \pm 1.6(29.1-33.8)$ \\
\hline b & 6.6 & $6.47 \pm 0.6(5.1-8.1)$ & $5.96 \pm 0.6(5.2-8.6)$ \\
\hline$b^{\prime}$ & 5.8 & $5.6 \pm 0.5(4.6-6.8)$ & $5.5 \pm 0.5(4.8-7.7)$ \\
\hline c & 44.4 & $46.4 \pm 3.1(41-55)$ & $33.7 \pm 2.5(30.5-38.1)$ \\
\hline$c^{\prime}$ & 1.1 & $1.0 \pm 0.1(0.8-1.2)$ & $1.6 \pm 0.1(1.5-1.8)$ \\
\hline $\mathrm{V}(\%)$ or $\mathrm{T} \%$ & 60.0 & $60.0 \pm 0.02(54-64)$ & $33.3 \pm 1.7(30-38)$ \\
\hline G1 (\%) & 38.3 & $31.2 \pm 5.3 .0(21.2-41.6)$ & - \\
\hline G2 (\%) & 35.8 & $29.3 \pm 3.0(21-36)$ & - \\
\hline N. lip annuli & 6.0 & $(5-6)$ & $(5-6)$ \\
\hline Lip width $(\mu \mathrm{m})$ & 7.7 & $7.5 \pm 0.2(7.3-8)$ & $7.2 \pm 0.3(6.5-7.8)$ \\
\hline Lip height $(\mu \mathrm{m})$ & 3.9 & $4.1 \pm 0.3(3.6-5.3)$ & $4.0 \pm 0.3(3.5-4.6)$ \\
\hline Stylet length & 25.2 & $25.6 \pm 0.5(24.7-26.4)$ & $22.7 \pm 0.8(21.4-24)$ \\
\hline Conus & 10.5 & $10.6 \pm 0.4(10.2-11.5)$ & $9.8 \pm 1.0(7.4-11.5)$ \\
\hline D.G.O. & 4.2 & $4.31 \pm 0.7(2.8-5.4)$ & $4.5 \pm 0.7(3.3-5.8)$ \\
\hline $\mathrm{O}(\%)$ & 16.7 & $16.8 \pm 2.9(10.6-21.3)$ & $5.1 \pm 0.8(4.1-6.9)$ \\
\hline Anterior end to centre of median bulb & 86.0 & $90.3 \pm 5.1(82-99)$ & $78.6 \pm 7.2(65-95)$ \\
\hline Anterior end to excretory pore & 124.0 & $118.4 \pm 9.8(103-141)$ & $111 \pm 8.9(91-127)$ \\
\hline Nerve ring & 116.0 & $107 \pm 10.5(97-121)$ & $103.6 \pm 8.1(88-119)$ \\
\hline Pharynx length $(\mu \mathrm{m})$ & 130.0 & $140.4 \pm 11.4(119-159)$ & $131.0 \pm 13.3(96-156)$ \\
\hline Pharyngeal overlap $(\mu \mathrm{m})$ & 24.0 & $29.4 \pm 5.2(21-40)$ & $15.0 \pm 1.9(11.8-19)$ \\
\hline Max. body diam. $(\mu \mathrm{m})$ & 28.0 & $27.8 \pm 1.0(26-29.5)$ & $22.5 \pm 0.8(20-24)$ \\
\hline Anal/cloacal body diameter $(\mu \mathrm{m})$ & 16.0 & $16.2 \pm 1.0(14.2-18)$ & $12.7 \pm 0.8(11.2-14.5)$ \\
\hline Tail length $(\mu \mathrm{m})$ & 17.0 & $16.8 \pm 1.1(15-20)$ & $21.6 \pm 1.3(19.4-24.8)$ \\
\hline Tail annuli & 11.0 & $10.0 \pm 0.8(9-12)$ & - \\
\hline Phasmid to terminus ( $\mu \mathrm{m})$ & 25.0 & $25 \pm 2(22-31.5)$ & $24.2 \pm 1.0(22.4-26.6)$ \\
\hline Spicules $(\mu \mathrm{m})$ & - & - & $27.9 \pm 1.2(26-31)$ \\
\hline Gubernaculum $(\mu \mathrm{m})$ & - & - & $11.6 \pm 0.9(10-13)$ \\
\hline Testis length $(\mu \mathrm{m})$ & - & - & $323.0 \pm 33.3(230-387)$ \\
\hline
\end{tabular}


Female, habitus ventrally curved to C-shaped. Body $0.7-0.8 \mathrm{~mm}$ long. Lip region rounded to hemispherical, offset with five to six annules and without longitudinal lines. Labial disc not distinct. Cephalic framework strongly sclerotized. Lateral field areolated from middle of stylet to pharyngeal region only. Stylet $24-26 \mu \mathrm{m}$, conus slightly shorter than shaft $(10 \mu \mathrm{m})$ and basal knobs rounded. Dorsal pharyngeal gland orifice 3-5.5 $\mu \mathrm{m}$ posterior to stylet base. Excretory pore $70-118 \mu \mathrm{m}$ from anterior end. Median bulb oval to rounded, isthmus short, encircled with nerve ring at anterior level. Basal glandular lobe of pharynx fairly variable in size from 21 to $40 \mu \mathrm{m}$ long. Excretory pore 95-141 $\mu \mathrm{m}$ from anterior level. Genital system didelphic with paired, equally developed ovaries, oocytes arranged in a single row. Spermatheca rounded filled with sperms. Vulva a depressed transverse slit and epiptygma not seen. Phasmid position at level of anus varying from two to five annuli anterior to anus. Tail rounded, slightly curved ventrally $15-20 \mu \mathrm{m}$ or $10-12$ annuli long.

Male, common, as abundant as female. Habitus ventrally curved. Body length slightly shorter than females, 0.6-0.7 $\mu \mathrm{m}$ long. Labial region identical to female. Stylet slightly shorter and weaker than that of female, 21-24 $\mu \mathrm{m}$ long; basal knobs rounded. Dorsal pharyngeal gland orifice 3.3-5-8 $\mu \mathrm{m}$ long, posterior to stylet knobs. Excretory pore 100-127 $\mu \mathrm{m}$ from anterior end. Testis outstretched. Spicule simple, 26-31 $\mu \mathrm{m}$ long and resting on 10-13 $\mu \mathrm{m}$ long gubernaculum. Bursa varying on length 36-62 $\mu \mathrm{m}$ and enveloping tail. Phasmids position at level of anus. Tail conoid, 19-25 $\mu \mathrm{m}$ long (Figures 1\&2).

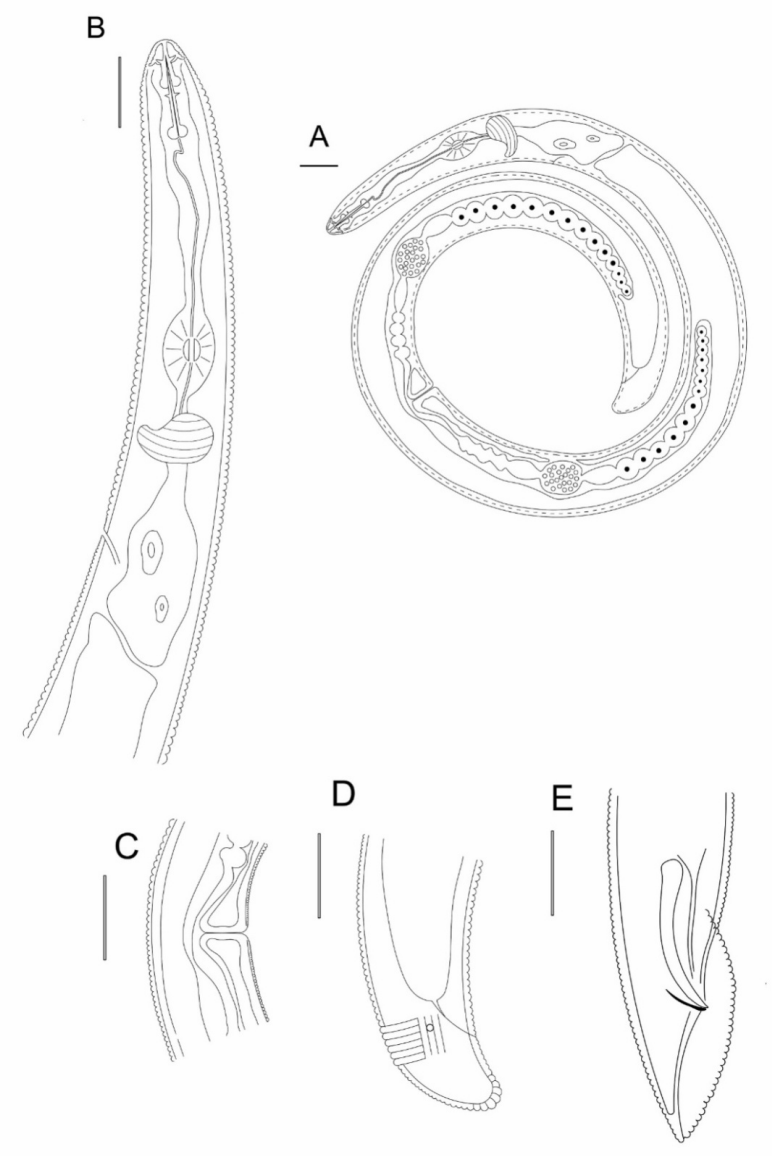

Figure 1. Rotylenchus conicaudatus, A) entire female, B) female labial region, C) vulva region, D) female tail, and E) mail tail (scale bars: $20 \mu \mathrm{m})$ 

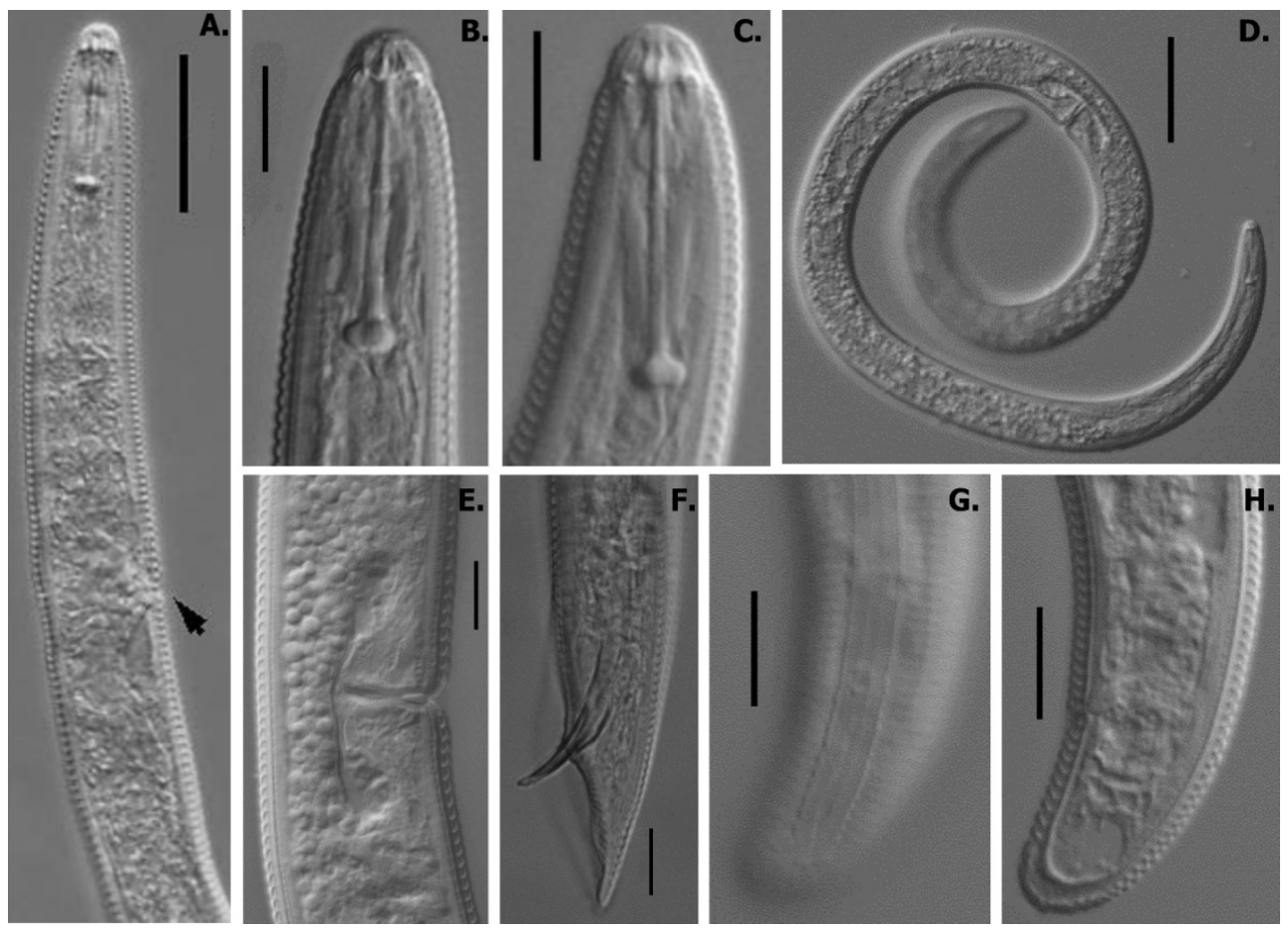

Figure 2. Photomicrographs of Rotylenchus conicaudatus: A) female pharyngeal region, B) female lip region, C) male lip region, D) whole body, E) vulval region, F) male tail, G) female tail (showing phasmid and lateral fields), and $\mathrm{H}$ ) female tail (Scale bars: A: $30 \mu \mathrm{m}$; D: $60 \mu \mathrm{m}$; and B, C, E, F, G and H: $10 \mu \mathrm{m})$.

Remarks. Morphology of $R$. conicaudatus from Mount Ararat showed slight differences in morphometrics from $R$. conicaudatus from Iran in having (i) an offset and hemispherical head region vs conoid-rounded lip region (Figures 3\&4); (ii) shorter body $(724-882 \mu \mathrm{m}$ vs 758-1049 $\mu \mathrm{m}$ ), (iii) shorter stylet $(25-26 \mu \mathrm{m}$ vs $27-32 \mu \mathrm{m})$ and (iv) shorter stylet cone $(10 \mu \mathrm{m}$ vs $15 \mu \mathrm{m})$ with less developed and rounded knobs vs wider knobs on $R$. conicaudatus (4.0-4.5 $\mu \mathrm{m}$ vs 5.0-6.5 $\mu \mathrm{m}$ ) (Atighi et al. 2011).
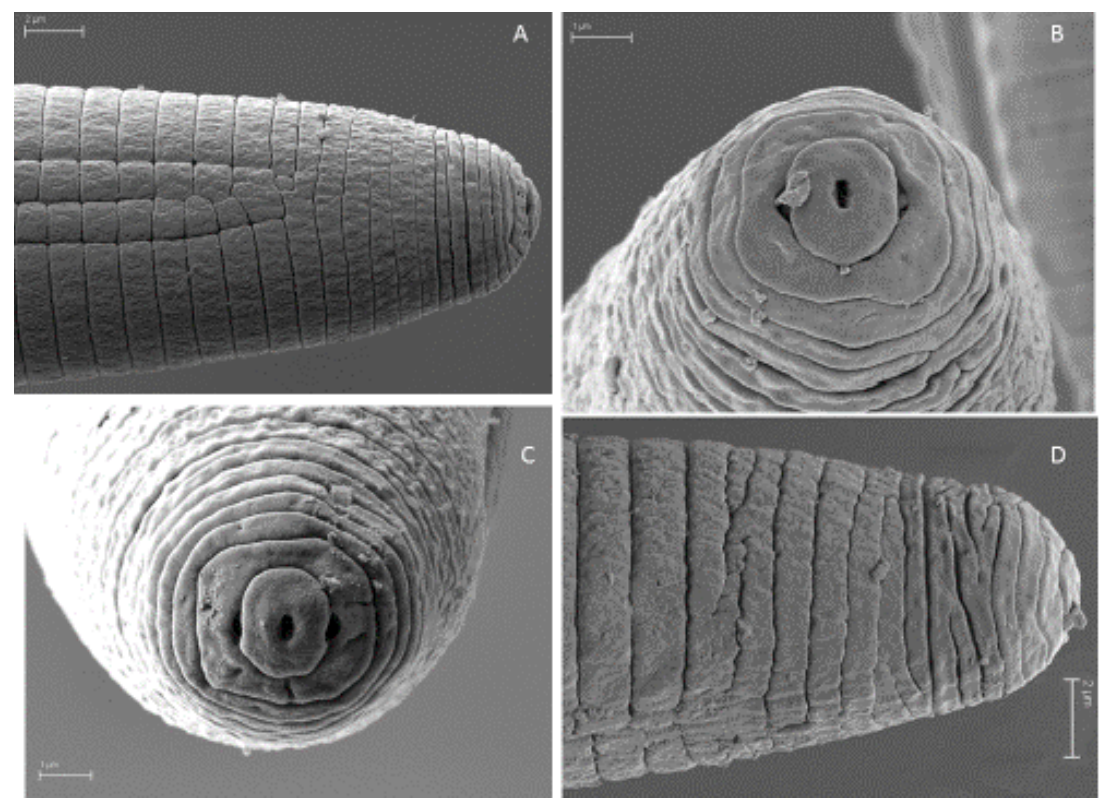

Figure 3. SEM pictures of Rotylenchus conicaudatus: A) anterior region in lateral view, B and C) lip region in frontal view, and D) anterior region in ventral view. 


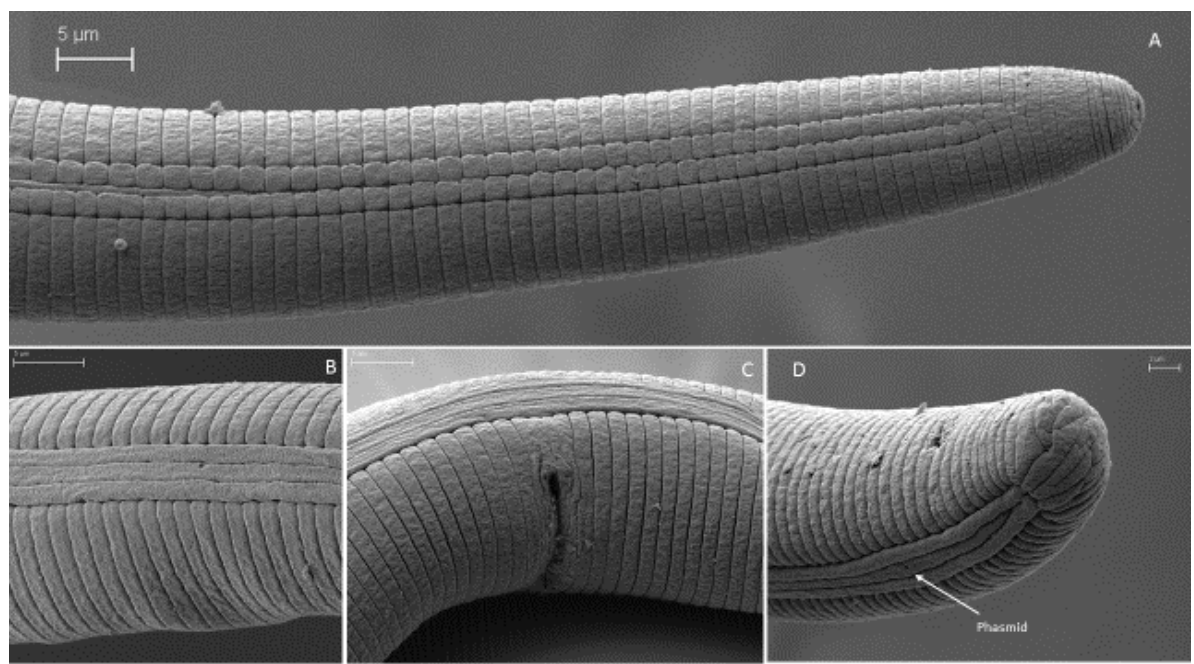

Figure 4. SEM pictures of Rotylenchus conicaudatus: A) lateral field at neck region, B) lateral lines, C) vulva region, and D) female tail.

The phylogenetic analysis based on the ITS-rRNA gene confirmed the identification of $R$. conicaudatus. Figures 5 and 6 presents the $50 \%$ majority rule consensus phylogenetic tree generated with 17 aligned sequences of Rotylenchus spp, from the ITS1 rRNA alignment by Bayesian analysis. The tree confirmed and supported that specimens from Mount Ararat were closely related with $R$. conicaudatus even though there are some morphological difference with the Iranian population. It is clear that there must be further studies on these two population with more different gene regions (Atighi et al., 2011).

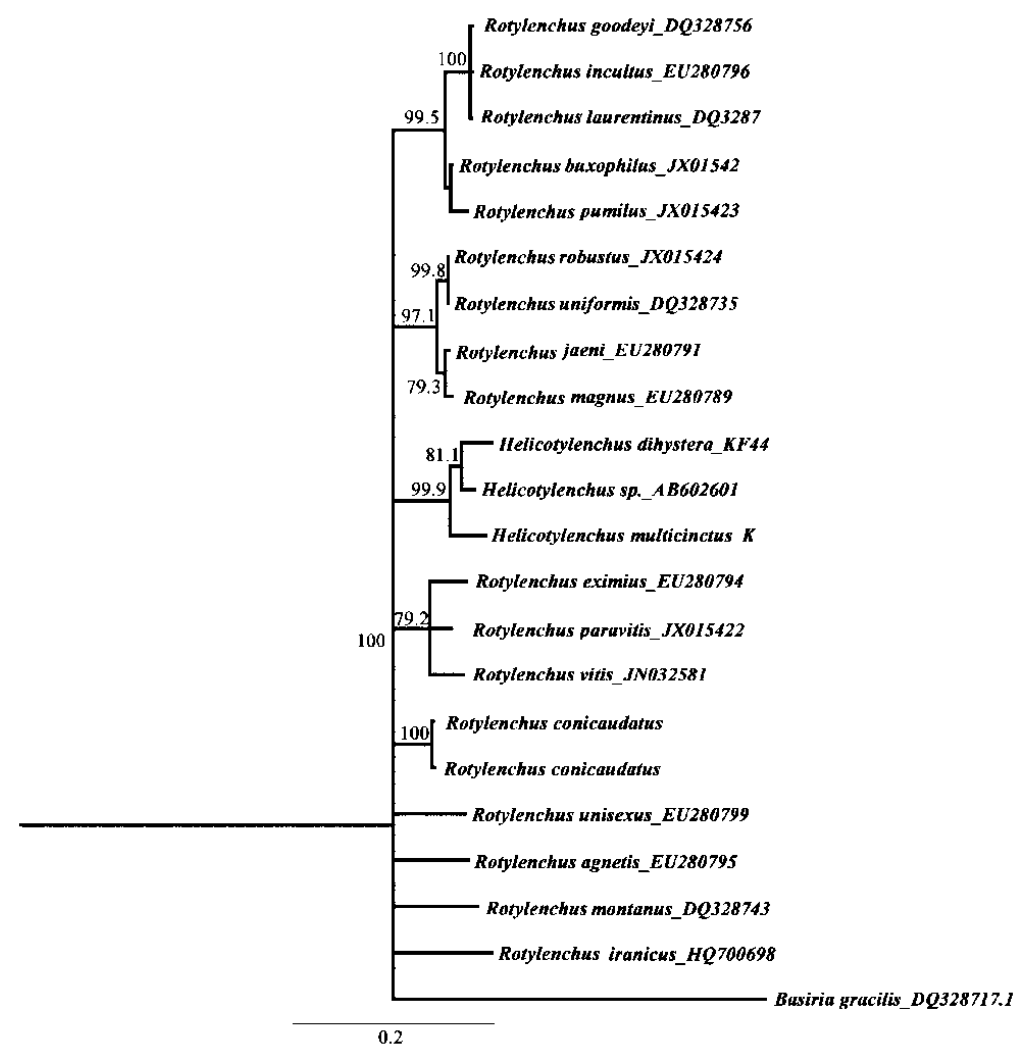

Figure 5. Bayesian inference $50 \%$ majority rule consensus phylogeny, generated from the D2-D3 of $28 \mathrm{~S}$ rRNA gene dataset of Rotylenchus conicaudatus and other closely related species sequences from GenBank. Basiria gracilis (Thorne, 1949) was selected as outgroup. 


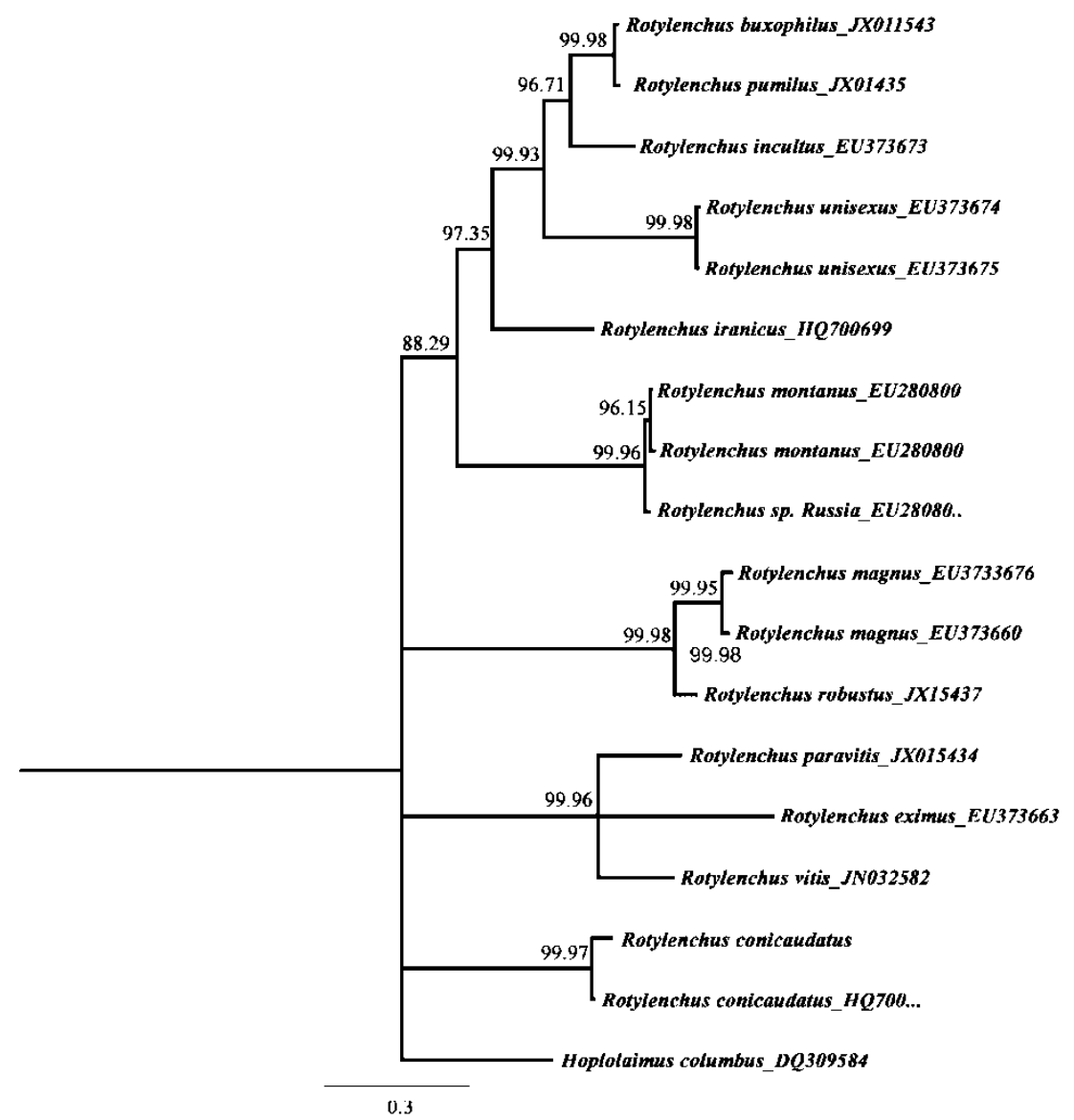

Figure 6. Bayesian inference $50 \%$ majority rule consensus phylogeny, generated from the ITS-rRNA gene dataset of Rotylenchus conicaudatus and other closely related species sequences from GenBank. Hoplolaimus columbus Sher, 1963 was selected as outgroup.

\section{Heteroderidae}

\section{Heterodera trifolii Goffart, 1932}

Material examined. Mount Ararat, Turkey, 23.VII.2013, three second stage juveniles, altitude $2952 \mathrm{~m}$ a.s.l., in riverbed.

\section{Description (Table 4).}

Second stage juvenile, body straight, 0.43-0.5 $\mu \mathrm{m}$. Head offset, cephalic framework heavily sclerotized. Lip region with four annules. Stylet robust $(\geq 28 \mu \mathrm{m})$, anchor shape, anteriorly concave. Dorsal gland orifice short, $3.3 \mu \mathrm{m}$ posterior to spear knobs. Subventral pharyngeal glands extending ventrally to intestine junction. Conoid tail uniformly tapering to a finely rounded terminus. Hyaline portion occupies $55 \%$ of total tail length. Phasmids located at the middle level of tail.

Remarks. Heterodera trifolii has a wide host range (Siddiqi, 2000) including plants in the Caryophyllaceae, Leguminosae and Polygonaceae. However, we collected H. trifolii on a species in the Poaceae.

Phylogenetic analysis. The phylogenetic relationships of the $H$. trifolii isolate from Mount Ararat were inferred from large subunit rDNA sequences (D2/D3 domains of the $28 \mathrm{~S}$ gene) including 24 selected species of Heterodera (Figure 7). The H. trifolii isolate from Iran (Heydari et al., 2010) was identical to $H$. trifolii from Mount Ararat without any single nucleotide difference. 


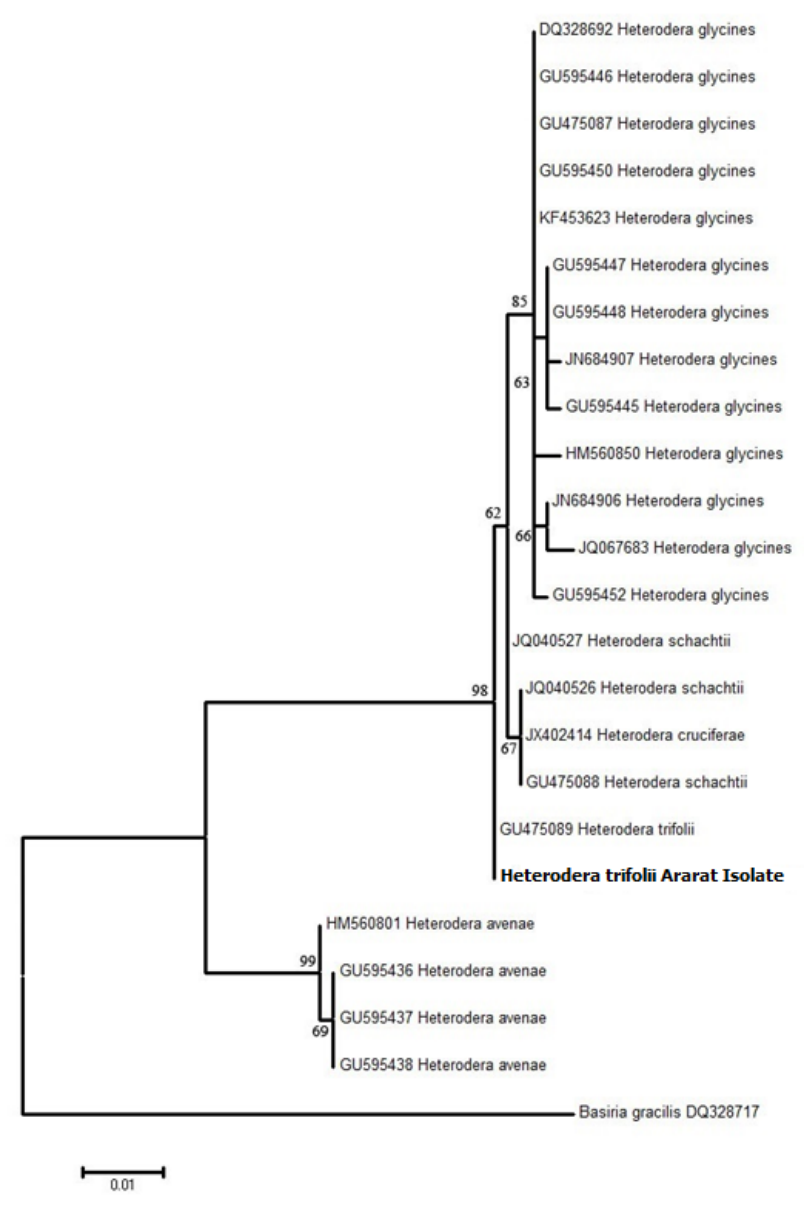

Figure 7. Bayesian inference $50 \%$ majority rule consensus phylogeny, generated from the D2-D3 of $28 \mathrm{~S}$ rRNA gene data set of Heterodera species sequences from GenBank. Basiria gracilis was designated as outgroup.

\section{Pratylenchidae}

\section{Pratylenchus neglectus (Reusch, 1924) Filipjev and Schuurmans Stekhoven, 1941}

Material examined. Mount Ararat, Turkey, 23.VII.2013, 1 q, altitude 3372 m a.s.l., in wildflower meadow.

Description (Table 4).

Female, body small. Labial region bluntly rounded, the dorsal and ventral submedian lips are fused, labia with two annules, second annulus wider than first. Lateral fields with four lines. Stylet knobs 4-6 $\mu \mathrm{m}$ across, typically indented on anterior surfaces. Pharyngeal gland overlapping intestine ventrally or ventrolaterally, subventral gland nuclei at end of lobes, not in tandem. Excretory pore $75 \mu \mathrm{m}$ from anterior end. Hemizonid immediately anterior to excretory pore. Female reproductive system monodelphic, prodelphic, ovary outstretched with oocytes in tandem, reaching to base of pharynx. Postvulval uterine sac less than corresponding body diameter. Tail conoid with little curvature of ventral surface and with 15 annules. Tail terminus without annulation, rounded. Phasmids in posterior half of tail.

Male, not found. 
Table 4. Morphometrics of plant parasitic species from Mount Ararat (measurements in $\mu \mathrm{m}$ )

\begin{tabular}{|c|c|c|c|c|c|}
\hline \multirow{2}{*}{ Characters } & \multirow{2}{*}{$\begin{array}{l}\text { Heterodera trifolii } \\
\qquad 3 \mathrm{~J} 2\end{array}$} & \multirow{2}{*}{$\begin{array}{c}\text { Pratylenchus neglectus } \\
\uparrow\end{array}$} & \multirow{2}{*}{$\begin{array}{c}\text { Pratylenchus thornei } \\
+\end{array}$} & \multicolumn{2}{|c|}{ Malenchus sp. } \\
\hline & & & & $2 ㅇ+9$ & 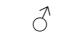 \\
\hline $\mathrm{n}$ & 3 & 1 & 1 & 2 & 1 \\
\hline $\mathrm{L}(\mathrm{mm})$ & $0.43-0.5$ & 0.4 & 0.5 & $0.32-0.33$ & 0.36 \\
\hline a & $21.0-24.0$ & 24.3 & 29.9 & $26.5-27.8$ & 25.2 \\
\hline b & $3.1-3.8$ & 6.8 & 7.4 & 3.8 & 3.9 \\
\hline$b^{\prime}$ & - & 5.8 & 5.6 & - & - \\
\hline c & 8.6-11.6 & 20.9 & 18.6 & 3.3 & 3.6 \\
\hline$c^{\prime}$ & 3.1-4.1 & 1.9 & 2.1 & 10.5 & 9.2 \\
\hline $\mathrm{V}(\%)$ or $\mathrm{T} \%$ & 57 & 79 & 75 & 82 & $?$ \\
\hline N. lip annuli & - & 2 & 3 & - & - \\
\hline Lip width $(\mu \mathrm{m})$ & 10.0 & 7.1 & 6.8 & $4.7-4.9$ & 4.5 \\
\hline Lip height $(\mu \mathrm{m})$ & $4.3-4.5$ & 2.4 & 3.1 & $3.0-3.1$ & 2.8 \\
\hline Stylet $(\mu \mathrm{m})$ & 28.3 & 15.7 & 16.3 & $11.5-11.7$ & 10.8 \\
\hline D.G.O. & 3.3 & 3.0 & 2.4 & - & - \\
\hline Ex. Pore & $102-109$ & 75 & 79 & $55-58$ & 59 \\
\hline Nerve ring & $83-86$ & 49 & 60 & $47-49$ & 51 \\
\hline Pharynx length $(\mu \mathrm{m})$ & $114-162$ & 58 & 72 & $81-87$ & 85 \\
\hline Pharyngeal overlap $(\mu \mathrm{m})$ & - & 20 & 27 & - & - \\
\hline Max. body diam. $(\mu \mathrm{m})$ & 20.5 & 16.1 & 18.0 & 12.0 & 11.5 \\
\hline $\mathrm{ABD}(\mu \mathrm{m})$ & 14.0 & 9.8 & 13.0 & $9.1-9.5$ & 9.0 \\
\hline Tail length $(\mu \mathrm{m})$ & 58.0 & 18.8 & 27.8 & $98-101$ & 91.5 \\
\hline Spicules $(\mu \mathrm{m})$ & - & - & - & - & 14 \\
\hline Gubernaculum $(\mu \mathrm{m})$ & - & - & - & - & 3 \\
\hline
\end{tabular}

Remarks. Identification of genus Pratylenchus is quite complex. Although it is difficult to justify the identification of $P$. neglectus based on only one individual specimen, the specimen examined closely matched to the published descriptions.

\section{Pratylenchus thornei Sher \& Allen}

Material examined. Mount Ararat, Turkey, 23.VII.2013, 1 \%, altitude 2552 and 2554 m a.s.I., in chalk grassland and mountain grassland.

\section{Description (Table 4).}

Female, body small $(0.5 \mathrm{~mm})$, slender, slightly ventrally curved after fixation. Lateral fields with four lines, outer ones straight or weakly crenate. Labial region with three annules, not offset from body. Stylet relatively short $(16 \mu \mathrm{m})$ with rounded knobs. Stylet guiding apparatus extending posteriorly from basal 
plate. Dorsal gland orifice (DGO) $3 \mu \mathrm{m}$ posterior to stylet base. Nerve ring immediately posterior to pharyngeal bulb, hemizonid located one annulus anterior to excretory pore. Ovary not extending up to pharynx. Oocytes in single row, oviduct indistinct, uterus short. Spermatheca obscure, postvulval uterine sac slightly more than 1.5 vulval body diam. long. Phasmids slightly posterior to midtail region, all four incisures extending posterior to phasmids. Tail dorsally convex-conoid with truncate terminus.

Male, not found.

Remarks. The material examined closely matched the published descriptions. A further phylogenetic analysis was made for a precise identification.

\section{Telotylenchidae}

\section{Nagelus camelliae (Kheiri, 1972) Siddiqi, 1979}

Material examined. Mount Ararat, Turkey, 23.VII.2013, 4 q , altitude 4184, 3972, and $3757 \mathrm{~m}$ a.s.I., in wildflower meadow and mountain grassland.

Description (Table 5).

Female, body 0.8-0.9 mm, slightly ventrally curved after fixation. Lateral field with six incisures. Labial region slightly offset, with five annules. Cephalic framework weakly sclerotized. Stylet slender, 25$27 \mu \mathrm{m}$ long with large knobs, sloping posteriorly. DGO 4.5-5.5 $\mu \mathrm{m}$ long. Pharynx 120-132 $\mu \mathrm{m}$, median bulb oval. Nerve ring position slightly posterior to excretory pore. Body diameter 23-25 $\mu \mathrm{m}$ at midbody. Vulva equatorial (50\%), vagina with thin walls. Spermatheca dorsally slightly offset. Tail conical, $72-78 \mu \mathrm{m}$ long.

Male, not found.

Remarks. According to our observations, N. camelliae species from Mount Ararat have longer body (0.8-0.9 mm vs $0.59-0.73 \mathrm{~mm})$ and longer tail $(72-78 \mu \mathrm{m}$ vs $39-51 \mu \mathrm{m})$ comparing with the original description (Geraert, 2019).

\section{Nagelus hexagrammus (Sturhan, 1966) Siddiqi, 1970}

Material examined. Mount Ararat, Turkey, 23.VII.2013, $1+$ and $4 \widehat{\partial} \widehat{\partial}$, altitude 2337 and $1900 \mathrm{~m}$ a.s.l., in wildflower meadow and mountain grassland.

Description (Table 5).

Female, body $1.3 \mathrm{~mm}$, slightly ventrally curved after fixation. Lateral field with six lines, occupying one-third of corresponding body diameter. Deirids finely visible on fourth line. Body slightly narrowing anteriorly, labial region with six annules, and cephalic framework prominent and strong. Stylet robust, $30 \mu \mathrm{m}$ long, knobs somehow laterally elongated. DGO $6.7 \mu \mathrm{m}$. Pharynx long, $185 \mu \mathrm{m}$ with oval median bulb. Nerve ring at $80 \%$ of pharynx length. Excretory pore anterior to basal bulb and more or less at the same level of nerve ring. Cardia hemispherical. Max width $30 \mu \mathrm{m}$ at midbody. Genital branches short. Tail conical, $74 \mu \mathrm{m}$.

Male, general morphology of males are same as female. Body 1.0-1.3 mm. Stylet length 30-33 $\mu \mathrm{m}$. DGO slightly longer than female, 7.5-8.5 $\mu \mathrm{m}$. Tail longer than female, 95-104 $\mu \mathrm{m}$. Spicules 32-36 $\mu \mathrm{m}$, gubernaculum 11-13 $\mu \mathrm{m}$. Anal body diameter 11-13 $\mu \mathrm{m}$, bursa narrow, enveloping the terminus. 
Remarks. This species was described from Germany and reported from Turkey (Elekçioğlu, 1996). Nagelus hexagrammus population from Mount Ararat closely matches the original description.

Table 5. Morphometrics of plant parasitic species from Mount Ararat (all measurements in $\mu \mathrm{m}$ )

\begin{tabular}{|c|c|c|c|c|c|c|c|c|}
\hline \multirow{2}{*}{ Characters } & \multicolumn{2}{|c|}{ Geocenamus koreanus } & \multirow{2}{*}{$\begin{array}{c}\text { Nagelus } \\
\text { camelliae } \\
\text { 우우 }\end{array}$} & \multicolumn{2}{|c|}{$\begin{array}{c}\text { Nagelus } \\
\text { hexagrammus }\end{array}$} & \multicolumn{2}{|c|}{$\begin{array}{c}\text { Tylenchorhynchus } \\
\text { mangiferae }\end{array}$} & \multirow{2}{*}{$\begin{array}{c}\text { Tylenchorhynchus } \\
\text { maximus } \\
\text { o }\end{array}$} \\
\hline & 우우 & $\widehat{\partial} \widehat{\partial}$ & & 우 & $\hat{\partial} \hat{O}$ & 우우 & $\widehat{\partial} \widehat{\partial}$ & \\
\hline $\mathrm{n}$ & 5 & 5 & 4 & 1 & 4 & 3 & 2 & 1 \\
\hline $\mathrm{L}(\mathrm{mm})$ & $0.69-0.76$ & $0.67-0.72$ & $0.8-0.9$ & $1.1-1.3$ & $1.0-1.3$ & $0.61-0.65$ & $0.54-0.58$ & 1.1 \\
\hline a & $28.0-29.0$ & $26.0-28.0$ & $31.0-32.0$ & 37.3 & $36.0-38.1$ & $31.6-31.8$ & $32.5-33.1$ & 44.7 \\
\hline b & $6.4-8.6$ & $6.5-8.4$ & $6.4-7.2$ & 6.0 & 6.1 & $5.1-5.4$ & $5.8-6.0$ & 6.9 \\
\hline$b^{\prime}$ & - & - & - & - & - & - & - & - \\
\hline c & $12.5-13.0$ & $11.0-13.5$ & $10.0-11.5$ & 15.1 & 11.5 & $12.0-12.5$ & 8.1 & 19.1 \\
\hline$c^{\prime}$ & $3.1-3.3$ & $2.9-3.2$ & $4.2-5.1$ & 2.9 & 4.7 & 3.5.3.6 & $3.0-3.3$ & 3.3 \\
\hline $\mathrm{V}(\%)$ or $\mathrm{T} \%$ & $54-56$ & $38-40$ & 50 & 54 & $33-35$ & $54-56$ & 42 & 50 \\
\hline N. lip annuli & 6 & 6 & 5 & 6 & 6 & 5 & 5 & 5 \\
\hline Lip width $(\mu \mathrm{m})$ & $8.1-9.5$ & $8.2-9.0$ & 7.3-7.7 & 8.2 & $8.6-8.9$ & 7.3-7.5 & 7.1-7.3 & 8.0 \\
\hline Lip height $(\mu \mathrm{m})$ & $3.2-5.5$ & $3.3-5$ & $4.2-4.5$ & 5.0 & $5.4-5.8$ & 3.5-3.7 & $3.2-3.4$ & 3.7 \\
\hline Stylet $(\mu \mathrm{m})$ & $20.0-22.0$ & $19.0-21.0$ & $25.0-27.0$ & 30.0 & $30.0-33.0$ & $18.2-18.8$ & $18.0-18.5$ & 23.7 \\
\hline D.G.O. & $2.2-3.4$ & $2.0-3.2$ & $4.3-5.6$ & 6.7 & 7.5.8.5 & $2.0-3.0$ & $2.5-3.0$ & 4.0 \\
\hline Ex. Pore & $85-97$ & $79-86$ & $102-110$ & 150 & $154-156$ & $111-114$ & $110-113$ & 154 \\
\hline Nerve ring & $68-84$ & $65-72$ & $98-102$ & 142.0 & $140-147$ & $63-74$ & $66-72$ & 69 \\
\hline Pharynx length $(\mu \mathrm{m})$ & $109-119$ & $105-112$ & $120-132$ & 185 & $180-193$ & $120-136$ & $118-120$ & 162 \\
\hline Max. body diam. $(\mu \mathrm{m})$ & $22.3-24.0$ & 22.0 & 23.4-25.0 & 30.0 & 31.0 & $19.5-20.0$ & 18.0 & 25.0 \\
\hline $\mathrm{ABD}(\mu \mathrm{m})$ & $17.0-19.0$ & 18.0 & $17.0-18.0$ & 26.0 & $19.0-22.0$ & $14.5-15.0$ & 14.0 & 18.0 \\
\hline Tail length $(\mu \mathrm{m})$ & $49.0-52.0$ & $55.0-72.0$ & $72.0-78.0$ & 74.0 & $95.0-104.0$ & $51.0-58.5$ & $64.0-66.0$ & 58.5 \\
\hline Spicules $(\mu \mathrm{m})$ & - & $25.0-27.0$ & - & - & $32.0-36.0$ & - & 26.5 & - \\
\hline Gubernaculum $(\mu \mathrm{m})$ & - & $6.1-7.2$ & - & - & $11.2-13.0$ & - & 7.7 & - \\
\hline
\end{tabular}




\section{Belonolaimidae}

\section{Tylenchorhynchus mangiferae (Luqman \& Khan, 1986)}

Material examined. Mount Ararat, Turkey, 23.VII.2013, 3 우 and 2 우, altitude 3372, 3140, and $1900 \mathrm{~m}$ a.s.I., in wildflower meadow and mountain grassland.

Description (Table 5).

Female, habitus slightly arcuate ventrally. Head slightly off set from body with five annules, rounded shape, lateral fields with four lines, occupying one-third of corresponding body width; Stylet not strongly developed with rounded knobs. DGO 2-3 $\mu$ m. Pharynx with oval median bulb and pyriform basal bulb, slightly distinct from intestine. Cardia hemispherical. Genital system amphidelphic with rounded spermathecae, vulva depressed, vagina appears with thin-walled structure. Tail bluntly rounded with fine annulations at terminus; pore-like phasmid at post anal region.

Male, crenate bursa surrounding tail. 22-23 $\mu \mathrm{m}$ long spicules, slightly ventrally curved, gubernaculum 8-10 $\mu \mathrm{m}$ long.

Remarks. Described from Uttar Pradesh, India. Tylenchorhynchus mangiferae population from Mount Ararat has a longer tail $(51-58 \mu \mathrm{m}$ versus $39 \mu \mathrm{m})$ than the type specimen.

\section{Tylenchorhynchus maximus (Allen, 1955)}

Material examined. Mount Ararat, Turkey, 23.VII.2013, 1 q, altitude 3563, 3140, and $3053 \mathrm{~m}$ a.s.I., in chalk grassland and mountain grassland.

Description (Table 5).

Female, habitus strongly arcuate. Body widely annulated, annuli width 1.3-1.6 $\mu \mathrm{m}$ on pharyngeal region, narrowing on mid body. Lateral field with 4 lines occupying 8-10 $\mu \mathrm{m}$ of corresponding body diameter. Head rounded and slightly set off from body, $8 \mu \mathrm{m}$ wide and $4 \mu \mathrm{m}$ high. Five to seven distinct annules present in head construction. Delicate stylet around 22-23 $\mu \mathrm{m}$ long with small knobs posteriorly slightly oblique. DGO $3 \mu \mathrm{m}$. Median bulb rounded, basal bulb pyriform off set from intestine. Cardia conoid. Vulva without epiptygma structure. Tail subcylindrical to cylindrical with 30-32 annules to broad terminus. Phasmids posterior to anus.

Male, not found.

Remarks. Tylenchorhynchus maximus is widely distributed in different continents, and was first described from New York, USA, and has since been reported from North America, Europe, Pakistan (Maqbool \& Shahina, 1987) and Trinidad (Gómez-Barcina et al., 1992). In our study morphometric measurements showed mostly the same numbers as it is described in Siddiqi, 2000.

\section{Dolichoridae}

\section{Geocenamus koreanus (Choi \& Geraert, 1971) Brzeski, 1991}

Material examined. Mount Ararat, Turkey, 23.VII.2013, 5 우 and $5 \hat{\jmath} \widehat{\jmath}$, altitude range 2337-3144 $\mathrm{m}$ a.s.l., in mountain grassland.

\section{Description (Table 5).}

Female, habitus, body slightly curved ventrally. Longitudinal striations are prominently formed, resembling divided blocks with the transverse striations, each of them with $1.5 \mu \mathrm{m}$ width. Lateral field occupying one fourth of the body width. Head slightly off set with six annules, and cephalic framework with six lips and slightly sclerotized. Conus of stylet very fine and delicate, measuring about $60 \%$ of the 
spear length, and surrounded by a guiding apparatus consisting of a tubular and oval part, and stylet knobs well developed and flattened anteriorly. DGO about $2 \mu \mathrm{m}$. Nerve ring positioned in $60 \%$ of pharynx length. Median bulb oval. Deirids obscure. Excretory pore near to posterior end of isthmus. Vulva not more than $4 \mu \mathrm{m}$ wide and provided with anterior and posterior epiptygma. Subcylindrical tail slightly tapering with widely rounded annulation at tip. Phasmids at posterior to anus.

Male, clearly developed hypoptygma observed in cloacal region. Conical and rounded tail. Bursa variable in size. Spicules 25-27 $\mu \mathrm{m}$ long, gubernaculum slightly curved and 6-7 $\mu \mathrm{m}$ long.

Remarks. Described from Korea and reported from Pakistan (Choi \& Geraert, 1972) Geocenamus koreanus population from Mount Ararat differs from type population with slightly shorter body and stylet length.

\section{Tylenchomorpha}

\section{Malenchus sp. Andrássy, 1968}

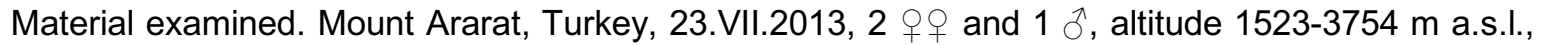
in mountain grassland, chalk grassland, wildflower meadow and marshland.

\section{Description (Table 4).}

Female, body slender, ventrally arcuate. Cuticle $1 \mu \mathrm{m}$ thick with fine transverse striae. Lateral field with crenate margins starting from $18 \mu \mathrm{m}$ from anterior end and occupying about one-third of body diameter. Head elevated and slightly offset from body by small depression. Stylet delicate, $10 \mu \mathrm{m}$ long with distinct knobs. Median bulb oval, basal bulb pyriform. Excretory pore 55-58 $\mu \mathrm{m}$ from anterior end. Female genital system prodelphic, ovary consisting single row of cells. Vulva transverse slit with vulval flaps at $82 \%$ of body length. Postvulval uterine sac short about $5 \mu \mathrm{m}$. Tail $98-101 \mu \mathrm{m}$, tapering gradually and pointed at tip.

Male, general appearance of both sexes similar. Spicules $14 \mu \mathrm{m}$, gubernaculum $3 \mu \mathrm{m}$ in length. Bursa about $32 \mu \mathrm{m}$ long.

Remarks. This species, showed closest relation to Malenchus kausari (Khan \& Ahmad, 1991) in morphology. However, Malenchus sp. from Mount Ararat differs in having abundance of males in population and in several morphometric characters such as the pharynx is longer longer (114-162 $\mu \mathrm{m}$ vs $71-97 \mu \mathrm{m})$ and the vulva position is more posterior ( $82 \%$ vs $59-64 \%$ in $M$. kausari). The latter is exceptional for the genus.

\section{Acknowledgments}

Support for this research was provided by the University of Ghent; Taylan Çakmak was supported by the European Master of Science in Nematology, Erasmus Mundus Master Programme during 20122014. We thank Mr. Prof. Dr. Pablo Castillo and Mr. Prof. Dr. Wim Bert for the deep assistance for the identification of the species.

\section{References}

Abolafia, J. \& R. Peña-Santiago, 2005. Nematodes of the order Rhabditida from Andalucía Oriental: Pseudacrobeles elongatus "de Man, 1880" comb. n. sp. Nematology, 7: 917-926.

Atighi, M. R., E. Pourjam, M. Pedram, C. Cantalapiedra-Navarrete, J. E. Palomares-Rius \& P. Castillo, 2011. Molecular and morphological characterizations of two new species of Rotylenchus (Nematoda: Hoplolaimidae) from Iran. Nematology, 13: 951-964.

Aydınlı, G., 2018. Detection of the root-knot nematode Meloidogyne luci 2014 (Tylenchida: Meloidogynidae) in vegetable fields of Samsun Province, Turkey. Turkish Journal of Entomology, 42: 229-237. 
Baermann, G., 1917. Eine einfache methode zur auffindung von Ankylostomum-(Nematoden) larven in erdproben. Weltevreden Batavia, Geneesk. Lab. Feestbundel, 41-47.

Blaxter, M. L., P. De Ley, J. R. Garey, L. X. Liu, P. Scheldeman, A. Vierstraete, J. R. Vanfleteren, L. Y. Mackey, M. Dorris, L. M. Frisse, J. T. Vida \& W. K. Thomas, 1998. A molecular evolutionary framework for the phylum Nematoda. Nature, 392: 71-75.

Cantalapiedra-Navarrete, C., J. A. Navas-Cortés, G. Liébanas, N. Vovlas, S. A. Subbotin, J. E. Palomares-Rius \& P. Castillo, 2013. Comparative molecular and morphological characterizations in the nematode genus Rotylenchus: Rotylenchus paravitis n. sp., an example of cryptic speciation. Zoologischer Anzeiger, 252: 246-268.

Choi, Y. E. \& E. Geraert, 1972. Some remarkable Tylenchida from Korea. Nematologica, 18: 66-73.

De Ley, I., P. De Ley, J. Baldwin, M. Mundo-Ocampo \& S. A. Nadler, 1999. Three new species of Nothacrobeles (Nemata: Cephalobidae) from the Mojave Desert, California. Journal of Nematology, 31: 482-497.

Elekçioğlu, İ. H., 1996. "Türkiye ve Doğu Akdeniz Bölgesi faunası için yeni bitki paraziti nematod türleri, 502-509". Türkiye 3. Entomoloji Kongresi Bildirileri (24-28 Eylül 1996, Ankara), 566s.

Elekçioğlu, I. H., B. Ohnesorge, G. Lung \& N. Uygun, 1994. Plant parasitic nematodes in the East Mediterrenaean Region of Turkey. Nematologia Mediterranea, 22: 59-63.

Erdal, F., F. Durmuş, İ. Kepenekçi \& M. E. Ökten, 2001. Türkiye'de tahıl baklagil endüstri bitkileri sebze meyve bağ ve turunçgil alanlarında saptanan Tylenchida Nematoda türlerinin ilk listesi. Turkish Journal of Entomology, 25: 49-64.

Geraert, E., 2019. The Dolichodoridae of the world: Identification of the family Dolichodoridae. Lannoo Publishers, Academia Press, London, 520 pp.

Gómez-Barcina, A., M. R. Siddiqi \& P. Castillo, 1992. The genus Bitylenchus Filipjev, 1934 (Nematoda: Tylenchida) with descriptions of two new species from Spain. Journal of the Helminthological Society of Washington, 59: 96-110.

Gözel, U. \& V. Yıldız, 2015. Ödemiş (İzmir) ilçesi sert ve yumuşak çekirdekli meyve fidanlıklarında bulunan bitki paraziti nematod faunası. Türkiye Entomoloji Bülteni, 5: 185-194.

Hall, T. A., 1999. BioEdit: A User-Friendly Biological Sequence Alignment Editor and Analysis Program for Windows 95/98/NT. Nucleic Acids Symposium Series, 41: 95-98.

Heydari, A. \& M. Pessarakli, 2010. A review on biological control of fungal plant pathogens using microbial antagonists. Journal of Biological Sciences, 10: 273-290.

Kepenekçi, I.., 2014. Plant parasitic nematodes Tylenchida Nematoda in Turkey. Pakistan Journal of Nematology, 32: 11-31.

Kepenekçi, I. \& M. E. Ökten, 2000a. Four new species for nematoda fauna of the Turkey belonging to Hoplolaimidae (Tylenchida: Nematoda) family as Rotylenchus agnetis Szczgiel, 1968; Helicotylenchus crenacauda Sher, 1966; H. striatus Firoza \& Maqbool, 1994 and Orientylus orientalis (Siddiqi \& Husain, 1964). Turkish Journal of Entomology, 24: 205-214.

Kepenekçi, İ. \& M. E. Ökten, 2000b. Türkiye nematod faunası için Dolichodoroidea (Tylenchida: Nematoda) üstfamilyasına bağlı yeni türler. Turkish Journal of Entomology, 24 (4): 301-316.

Kepenekçi, İ. \& M. E. Ökten, 2000c. Türkiye nematod faunası için Tylenchoidea ve Hoplolaimoidea (Tylenchida: Nematoda) üstfamilyalarına bağlı yeni türler ve Hoplolaimus galeatus Cobb 1913 Thorne 1935'un taksonomik özellikleri. Bitki Koruma Bülteni, 40 (1): 1-27.

Kepenekçi, İ. \& G. Öztürk, 2000. Türkiye nematod faunası için Pratylenchoides Winslow, 1958 (Nematoda: Pratylenchidae) cinsine bağı iki yeni tür. Turkish Journal of Entomology, 24 (2): 125-132.

Khan, T. H. \& W. A. S. I. M. Ahmad, 1991. Two known and three new species of Duosulciinae (Nematoda: Tylenchida). Indian Journal of Nematology, 19: 129-137.

Lambshead, P. J. D., 1993. Recent developments in marine benthic biodiversity research. Oceanis, 19: 5-24.

Maqbool, M. A. \& F. Shahina, 1987. Nematodes of northern areas in Pakistan. Description of Nagelus saifulmulukensis $\mathrm{n}$. sp. (Tylenchinae: Nematoda). Redia, 47: 119-122.

Mimee, B., H. Peng, V. Popovic, Q. Yu, M. O. Duceppe, M. P. Tetreault \& G. Belair, 2014. First report of soybean cyst nematode (Heterodera glycines Ichinohe) on soybean in the province of Quebec, Canada. Plant Disease, 98: 429. 
Mıstanoğlu, İ., G. Kaşkavalcı \& Z. Devran, 2015. İzmir ve Manisa illerinde bağ alanlarında ekonomik öneme sahip bitki paraziti nematodların morfolojik ve moleküler yöntemlerle tanılanması. Turkish Journal of Entomology, 39: 297-309.

Muşdağı, S. \& U. Gözel, 2015. Çanakkale ili lahana ekim alanlarında kist nematodu türlerinin (Heterodera spp.) belirlenmesi. Türkiye Entomoloji Bülteni, 5: 11-20.

Nelson, B. D., M. D. Bolton, H. D. Lopez-Nicora, T. L. Niblack \& L. del Rio Mendoza, 2012. First confirmed report of sugar beet cyst nematode, Heterodera schachtii, in North Dakota. Plant disease, 96 (5): 772.

Ökten, M. E., 1982. Ankara İlinde Yetiştirilen Sebzelerde Görülen Tylenhorhynchinae (Tylenchoidea, Dolichodoridae: Nematoda) Türleri Üzerinde Taksonomik, Morfolojik Araştırmalar. Ankara Üniversitesi Fen Bilimleri Enstitüsü, (Basılmamış) Doçentlik Tezi, $76 \mathrm{~s}$.

Ökten, M. E., İ. Kepenekçi \& H. C. Akgül, 2000. Distribution and host association of plant parastic nematodes (Tylenchida) in Turkey. Pakistan Journal of Nematology, 18: 79-106.

Peng, D. \& W. Ye, 2011. Phylogenetic analysis of Heterodera glycines from D2 and D3 fragments of the $28 \mathrm{~S}$ rRNA gene sequences. (Web page: https://www.ncbi.nlm.nih.gov/nuccore/GU595446.1) (Date accessed: 25.02.2019).

Peng, D. \& X. Xu, 2013. Phylogenetic analysis of Heterodera glycines from D2 and D3 fragments of the 28S rRNA gene sequences. (Web page: https://www.ncbi.nlm.nih.gov/nuccore/JQ067683) (Date accessed: 25.02.2019).

Ronquist, F. \& J. P. Huelsenbeck, 2003. MrBayes 3: Bayesian phylogenetic inference under mixed models. Bioinformatics, 19: 1572-1574.

Sasanelli, N., N. Vovlas, N. Trisciuzzi, C. Cantalapiedra-Navarrete, J. E. Palomares-Rius \& P. Castillo, 2013. Pathogenicity and host-parasite relationships of Heterodera cruciferae in cabbage. Plant disease, 97 (3): $333-338$.

Siddiqi, M. R., 2000. Tylenchida parasites of plants and insects. CABI Publishing, UK, 848 pp.

Subbotin, S. A., D. Sturhan, N. Vovlas, P. Castillo, J. Tanyi Tambe, M. Moens \& J. G. Baldwin, 2007. Application of secondary structure model of rRNA for phylogeny: D2-D3 expansion segments of the LSU gene of plantparasitic nematodes from the family Hoplolaimidae Filipjev, 1934. Molecular Phylogenetics and Evolution 43: 881-890.

Thompson, J. D., D. G. Higgins \& T. J. Gibson, 1994. CLUSTAL W: Improving the sensitivity of progressive multiple sequence alignment through sequence weighting, position-specific gap penalties and weight matrix choice. Nucleic Acids Research, 22: 4673-4680.

Vovlas, N., S. A. Subbotin, A. Troccoli, G. Liébanas \& P. Castillo, 2008. Molecular phylogeny of the genus Rotylenchus (Nematoda, Tylenchida) and description of a new species. Zoologica Scripta, 37: 521-537.

Vrain, T. C., D. A. Wakarchuk, A. C. Lévesque \& R. I. Hamilton, 1992. Intraspecific rDNA restriction fragment length polymorphism in the Xiphinema americanum group. Fundamental \& Applied Nematology, 15: 563-573.

Wei, Z., H. Li, Y. Liu \& M. Li, 2013. Phylogenetic analysis of Heterodera glycines from D2 and D3 fragments of the 28S rRNA gene sequences. (Web page: https://www.ncbi.nlm.nih.gov/nuccore/JN684907.2) (Date accessed: 25.02.2019).

Ye, W., D. Peng \& B. Xu, 2010. Phylogenetic analysis of Heterodera glycines from D2 and D3 fragments of the 28S rRNA gene sequences. (Web page: https://www.ncbi.nlm.nih.gov/nuccore/HM560801) (Date accessed: 25.02.2019).

Yoder, M., I. T. De Ley, I. W King, M. Mundo-Ocampo, J. Mann, M. Blaxter, L. Poiras, \& P. De Ley, 2006. DESS: A versatile solution for preserving morphology and extractable DNA of nematodes. Nematology, 8: 367-376. 